\title{
Gaok's Oral Tradition Document Management as a Manifestation of Cultural Preservation in The Library
}

\section{Pengelolaan Dokumen Tradisi Lisan Gaok sebagai Wujud Pelestarian Budaya di Perpustakaan}

Septa dan Heriyanto

Paper Type:

Universitas Diponegoro

Research Paper

\begin{abstract}
Background of the study: This research identifies ways of the document management of local oral traditions in Majalengka.

Purpose: It aims to uncover how the library has managed the local oral document which intended to preserve the Gaok local content.

Method: A qualitative method was implemented by using semi-structured interviews as a data collection technique. The collected data were then analyzed by using Thematic Analysis, which generates three themes related to the research questions. The themes are Motivation, Document Management, and Dissemination Planning.

Findings: Motivation describes the background of the initiative by managing the Gaok Oral Documents. While the second theme, Document Management, portrays the effort taken by the library in managing the documents, that include retrieving information about Gaok, writing its resume, and disseminate the information. Finally, the third theme, Dissemination Plan, describing the library strategic plans on disseminating and implementing their strategy of the Gaok Documents locally and nationally. The library believes that by managing the Gaok Oral Documents effectively, this local tradition will keep alive and known and hopefully preserved by the future generations.

Conclusion: This study reflects how a library plays an important role in managing and preserving local culture.
\end{abstract}

Keywords: Oral documents; Document management; Local Content;

Cultural preservation; Library and Information Research

Submitted 28 June 2019

* Correspondence : Septa 


\begin{abstract}
Abstrak
Latar Belakang Masalah: Penelitian ini mengidentifikasi bentuk pengelolaan dokumen tradisi lisan lokal di Majalengka.

Tujuan: Tujuan dari penelitian ini untuk mengetahui bentuk pengelolaan yang dilakukan oleh perpustakaan yang berada di daerah Majalengka dalam mengelola dokumen local content yang berupa tradisi lisan Gaok.
\end{abstract}

Metode Penelitian: Untuk mencapai tujuan tersebut, dipilih metode penelitian kualitatif, dengan menggunakan wawancara semiterstruktur sebagai teknik pengumpulan data. Data yang terkumpul kemudian dianalisis dengan menggunakan Thematic Analysis yang menghasilkan tiga tema, yaitu Motivasi, Pengelolaan, dan Perencanaan pustakawan dalam mengelola dokumen tradisi lisan Gaok.

Temuan: Tema pertama, motivasi yaitu menceritakan tentang latar belakang pengelolaan, sementara tema kedua, Pengelolaan, yaitu menceritakan upaya yang dilakukan pustakawan dalam mengelola dokumen tradisi lisan Gaok, diantaranya dengan melakukan penelusuran artikel Gaok, dilanjutkan dengan mengelola artikel yang diperoleh tersebut, serta dilanjutkan dengan menulis resensi Gaok sekaligus mendiseminasikannya. Tema ketiga, yaitu Perencanaan, seperti tersirat dalam namanya, bercerita tentang kegiatan perencanaan pustakawan dalam mencanangkan sekaligus mengimplementasikan rencanarencana pelestarian tradisi lisan Gaok, supaya tradisi tersebut tetap dikenal oleh masyarakat, khususnya generasi penerus, serta sebagai wujud untuk melestarikan budaya.

Kesimpulan: Berdasarkan keseluruhan kegiatan pengelolaan tradisi lisan Gaok ini dapat mencerminkan bagaimana seorang pustakawan dan lembaga perpustakaan menjalankan perannya sebagai pengelola hasil dari kebudayaan sekaligus pelestari budaya lisan.

Kata Kunci: dokumen lisan, pengelolaan dokumen, local content, pelestarian budaya 


\section{Pendahuluan}

Indonesia merupakan negara yang sangat luas. Luas wilayahnya membuat Indonesia memiliki banyak sekali kekayaan, baik dari segi kekayaan alam maupun kekayaan budaya. Kekayaan budaya yang dimiliki Indonesia sangatlah beragam dan menyisakan sebuah sejarah, artefak, serta di mana salah satunya ialah tradisi lisan. Tradisi lisan merupakan pesan verbal yang berupa pernyataan turuntemurun dapat disebarkan dan diajarkan kepada generasi masa kini melalui tuturan secara langsung atau dapat juga disampaikan dengan nyanyian, baik dengan bantuan alat musik atau tanpa alat musik (Vanisa dalam Sumitri, 2016: 6). Sejalan dengan pengertian tersebut, Ong (dalam Sumitri, 2016: 56) menyatakan bahwa tradisi lisan merupakan kelisanan suatu budaya yang sama sekali tidak tersentuh oleh pengetahuan apapun mengenai tulisan atau cetakan sebagai kelisanan primer. Namun seiring berjalannya waktu, tradisi lisan semakin mengarah kepada kepunahan. Kementerian dan Kebudayaan Indonesia (2018) menyampaikan bahwa Tradisi Lisan Gaok yang berasal dari Majalengka dinyatakan hampir punah.

Gaok adalah sebuah kesenian tradisional yang berasal dari Kabupaten Majalengka, tepatnya di Desa Kulur Majalengka Jawa Barat. Gaok merupakan sebuah pertunjukan wawacan, yakni membacakan cerita rakyat yang ditulis dengan pola tertentu berbentuk pupuh. Pupuh sendiri adalah bentuk puisi tradisional berbahasa Sunda yang memiliki jumlah kata atau irama di setiap barisnya. Seiring kehidupan masyarakat yang mengalami perubahan, Gaok tidak lagi berkembang. Gaok kini semakin jarang dipentaskan, beberapa tradisi masyarakat yang biasanya mengundang Gaok pun kini tidak lagi mementaskannya.

Dokumen lisan merupakan sebuah dokumen yang mampu menyampaikan bukti atau informasi ke dalam konten tertentu yang disampaikan melalui lisan (Duija, 2005; Turner, 2009). Definisi ini mencerminkan bagaimana sebuah dokumen dapat menyampaikan bukti lisan atau informasi dalam dua cara, yaitu dengan kata-kata dan tindakan. Turner mengungkapkan bahwa ucapan dapat menghasilkan suatu jenis dokumen tertentu. Misalnya, argumen lisan dan pidato formal. Bentuk-bentuk lain dari dokumen lisan dapat dengan jelas dipahami melalui konsep sejarah lisan atau tradisi lisan. Sejarah lisan adalah cerita tentang kehidupan seseorang, sementara tradisi lisan adalah pesan lisan diceritakan dari generasi ke generasi. (Vansina, 1985, p. 13, dikutip oleh Turner, 2015, p.861), sehingga dari adanya perkembangan dokumen tersebut telah memberikan ruang pada tradisi lisan Gaok sebagai bentuk dari dokumen lisan. Ancaman kepunahan tradisi lisan Gaok ini menjadi perhatian bagi perpustakaan. Hal ini, tak lain karena perpustakaan merupakan sebuah lembaga dokumenter yang mengelola segala jenis dokumen termasuk di dalamnya dokumen lisan, selain itu perpustakaan mempunyai kewajiban dalam melestarikan budaya karena telah diamanatkan pada Undang-Undang perpustakaan No 43 Tahun 2007, Pasal 8, butir f, yaitu kewajiban Perpustakaan umum Provinsi dan Kabupaten / Kota "menyelenggarakan dan mengembangkan perpustakaan umum daerah berdasarkan kekhasan daerah sebagai pusat penelitian dan rujukan tentang kekayaan budaya daerah di wilayahnya." Perpustakaan berkembang seiring dengan perkembangan kebudayaan suatu bangsa, bahkan perkembangan budaya bangsa tidak dapat lepas dari peran perpustakaan. Perpustakaan sebagai institusi pendidikan dan kebudayaan berfungsi dan berperan sebagai pelestari hasil budaya bangsa untuk kepentingan pendidikan, penelitian, informasi, dan rekreasi (Lasa Hs, 2009:5).

Pada artikel yang berjudul "The Role of Library in Managing Oral Document (Theoritical Studies on Indigenous Knowledge for Disaster Management in Simeuleu Island)" oleh Dian Novita Fitriani \& Niswa Nabila Sba (2017), bertujuan menggambarkan peran yang dapat dilakukan oleh perpustakaan dalam mengelola "smong" yang merupakan salah satu Pengetahuan Pribumi di Pulau Simeulue, dikarenakan perpustakaan merupakan lembaga dokumenter, sehingga perpustakaan memiliki peran untuk mengelola dokumen lisan dalam bentuk Pengetahuan Pribumi. Fitriani, menyimpulkan bahwa peranan yang dapat dilakukan oleh perpustakaan umum dalam mengelola dokumen lisan dengan cara Speech (pendokumentasian dokumen lisan melalui orangorang yang masih mengetahui dan memiliki pengetahuan terhadap dokumen lisan tersebut dengan 
cara wawancara, membuat video, ataupun rekaman), Posts (mendokumentasikan dokumen lisan dengan melakukan sebuah proyek penelitian atau penulisan dan Measures (mengelola dan memberdayakan masyarakat untuk terlibat langsung dalam pengelolaan dokumen lisan, karena pada dasarnya sebuah dokumen lisan tidak ada artinya tanpa sebuah praktek). Hal ini, menunjukan bahwa pengelolaan terhadap kekayaan budaya bangsa dalam bentuk dokumen lisan perlu untuk dilakukan oleh sebuah lembaga perpustakaan agar selalu terjaga dan terlestarikan.

Berdasarkan uraian tersebut, maka penelitian ini bertujuan untuk mengidentifikasi bentuk pengelolaan dokumen tradisi lisan Gaok yang dilakukan oleh perpustakaan sebagai wujud pelestarian budaya, sehingga diharapkan hasil dari penelitian ini dapat bermanfaat untuk memberikan pengetahuan baru terkait dengan tugas lembaga perpustakaan serta peranan pustakawan dalam mengelola dokumen tradisi lokal di suatu daerah.

\section{Metode Penelitian}

Penelitian ini dilakukan dengan menggunakan metode kualitatif, yang bertujuan untuk mengidentifikasi bentuk pengelolaan dokumen tradisi lisan Gaok yang dilakukan oleh perpustakaan. Pemilihan metode kualitatif dianggap tepat dikarenakan penelitian ini menjelaskan mengenai bentuk pengelolaan tradisi lisan Gaok yang dilakukan oleh perpustakaan, yang dijelaskan secara naratif dengan menggunakan kata-kata. Metode pengumpulan data dilakukan dengan dua cara, yaitu observasi dan wawancara semiterstruktur. Populasi dalam penelitian ini ialah orang-orang yang bekerja di perpustakaan yang berada di wilayah Majalengka, terdiri dari kepala dinas, kepala bidang, staff, serta pustakawan. Sedangkan sampel yang dipilih adalah pustakawan, dikarenakan pustakawan adalah pihak yang terlibat dalam pengelolaan tradisi lisan Gaok serta memiliki banyak pengetahuan tentang hal tersebut, sehingga proses wawancara dilakukan dengan pustakawan sebagai informan. Data yang diperoleh kemudian dianalisis dengan menggunakan Thematic Analysis, sebuah teknik menganalisis data kualitatif untuk mengidentifikasi pola atau pattern yang terjadi dalam sebuah fenomena yang sedang diteliti (Heriyanto, 2018). Teknik ini terdiri dari beberapa tahapan (Braun \& Clarke, 2006) diantaranya 1.) Familiarisasi dengan data (Familiarizing yourself with your data), yaitu mendengarkan lagi rekaman wawancara dan menuliskannya dalam bentuk transkrip. Kemudian, dilanjutkan dengan membuat kode, dikenal pula dengan istilah coding, tahapan dimana potongan-potongan data yang relevan dengan rumusan masalah diberikan kode atau label. Tabel 1 menunjukkan beberapa contoh kode yang dihasilkan.

Tabel 1. Beberapa contoh kode yang muncul

No Nama Kode

Motivasi menulis resensi

Mencetak dan menyimpan koleksi tentang Gaok

Rencana mengolah koleksi

Mencari informasi tentang Gaok

Mengirimkan karya tulis

Menulis resensi Gaok

Setelah semua data yang relevan dibuatkan kode, kode-kode tersebut kemudian dikelompokkan berdasarkan keserupaan makna yang terkandung di dalamnya. Dari pengelompokkan inilah kemudian bisa ditentukan tema (tahap ketiga). Tema merupakan representasi dari fenomena atau peristiwa yang sedang dikaji (Heriyanto, 2018). Nama-nama kelompok merupakan nama yang unik karena merupakan penggabungan dari kode-kode yang memiliki makna yang serupa, seperti yang disampaikan di Tabel 2. 
Tabel 2. Beberapa contoh kelompok yang muncul

\begin{tabular}{|c|c|c|}
\hline Grup & Kode & Nama \\
\hline 1 & $\begin{array}{l}\text { Motivasi pustakawan dalam melestarikan Gaok } \\
\text { Motivasi pustakawan dalam menulis resensi }\end{array}$ & Motivasi \\
\hline 2 & $\begin{array}{l}\text { Mencetak koleksi tentang Gaok } \\
\text { Menyimpan penelitian tentang Gaok } \\
\text { Mencetak dan menyimpan koleksi tentang Gaok }\end{array}$ & Pengolahan \\
\hline 3 & $\begin{array}{l}\text { Rencana menjilid koleksi } \\
\text { Rencana mengolah koleksi }\end{array}$ & $\begin{array}{l}\text { Perencanaan } \\
\text { Pengolahan Koleksi }\end{array}$ \\
\hline 4 & $\begin{array}{l}\text { Mencari informasi tentang Gaok } \\
\text { Memilah informasi yang dicari }\end{array}$ & Penelusuran Informasi \\
\hline 5 & Mengirimkan karya tulis (resensi Gaok) & Diseminasi \\
\hline 6 & Menulis resensi Gaok & Menulis \\
\hline
\end{tabular}

Nama-nama kelompok tersebut kurang lebih sudah menunjukkan pattern seputar fenomena pengelolaan tradisi lisan Gaok. Namun, mengikuti rekomendasi dari Braun \& Clarke (2006) bahwa masih mungkin terjadi kemiripan dalam nama-nama kelompok, maka nama-nama kelompok tersebut ditinjau ulang dan kelompok yang memiliki kemiripan makna dilebur menjadi satu kelompok yang kemudian menjadi tema. Tema yang muncul, seperti disampaikan ditabel 3, adalah Motivasi, Pengelolaan, dan Perencanaan.

Tabel 3. Tema Final yang ditemukan

\begin{tabular}{cll}
\hline No & \multicolumn{1}{c}{ Grup } & Tema Final \\
\hline 1 & Motivasi & Motivasi \\
2 & $\begin{array}{l}\text { Pengolahan } \\
\text { Penelusuran Informasi }\end{array}$ & Pengelolaan \\
& $\begin{array}{l}\text { Diseminasi } \\
\text { Menulis } \\
3\end{array}$ & $\begin{array}{l}\text { Perencanaan pengolahan koleksi } \\
\text { Perencanaan diseminasi } \\
\text { Perencanaan publikasi }\end{array}$ \\
& Perencanaan \\
\hline
\end{tabular}

\section{Hasil dan Diskusi}

Motivasi adalah tema pertama yang memotret keinginan pribadi pustakawan untuk melestarikan dokumen tradisi lisan Gaok. Ada beberapa hal yang menimbulkan motivasi pada diri pustakawan untuk melestarikan Gaok yaitu, adanya kekhawatiran pada diri pustakawan bahwa Gaok akan mengalami kepunahan apabila tidak segera dilestarikan. Meskipun tradisi Lisan Gaok merupakan seni kebudayaan yang berasal dari Desa Kulur Majalengka, namun pada kenyataannya tradisi ini masih sangat awam dan kurang dikenal oleh masyarakat, terlebih oleh masyarakat Majalengka. Faktor tidak populernya Gaok ini yang juga menjadi salah satu motivasi pustakawan dalam mengelola tradisi Lisan Gaok, agar Gaok dapat dilestarikan dan dapat lebih dikenal oleh masyarakat secara luas.

Motivasi kedua, terkait dengan pemenuhan tugas fungsional sebagai pustakawan. 
tentang Jabatan Fungsional Pustakawan dan Angka Kreditnya, ada keinginan pribadi bagi sebagian besar informan untuk meningkatkan pengetahuan dan kompetensi sebagai seorang pustakawan. Hal ini, selaras dengan penelitian yang dilakukan oleh Nashihuddin dan Aulianto (2015) yang menyampaikan bahwa pustakawan dituntut untuk meningkatkan kemampuan dan profesionalismenya supaya mampu menjawab tantangan di dunia informasi yang semakin mengglobal.

Motivasi lain dalam pelestarian Gaok adalah untuk mengisi waktu disela-sela tugas pokok, selain tugas mengelola manajemen perpustakaan, pelayanan perpustakaan, dan pengembangan sistem kepustakawanan, para informan menyampaikan bahwa masih menyempatkan sedikit waktu untuk mengisi dengan kegiatan-kegiatan terkait pelestarian budaya Gaok.

\section{Pengelolaan Tradisi Lisan Gaok}

Tema kedua adalah Pengelolaan Tradisi Lisan Gaok. Tema ini bercerita tentang bentuk atau cara yang dilakukan pustakawan dalam melestarikan dokumen Tradisi Lisan Gaok, meliputi penelusuran informasi, pengolahan, menulis, dan diseminasi.

\section{Penelusuran Informasi}

Pada saat melakukan pengelolaan, perpustakaan melakukan beberapa kegiatan, salah satunya dengan menelusuri informasi untuk mendapatkan artikel jurnal mengenai tradisi lisan Gaok. Tahun 2018, awal mula munculnya pemberitaan mengenai hampir punahnya Tradisi Lisan Gaok, faktor hampir punah inilah yang membuat Gaok berpotensi mengalami kepunahan apabila tidak segera dilestarikan, sehingga berangkat dari latar belakang tersebut, maka pustakawan segera melakukan langkah pertama untuk melestarikan tradisi lisan Gaok, dengan cara mencari informasi terkait artikel-artikel yang membahas mengenai tradisi lisan Gaok.

Artikel-artikel tentang Gaok mayoritas ditelusuri melalui situs-situs jurnal yang tersedia di Internet. Menurut informan, terdapat beberapa situs yang menampilkan penelitian tentang Gaok dan tulisan-tulisan tersebut yang bersifat open access, dimana hal tersebut sesuai dengan yang diharapkan informan di mana artikel-artikel tersebut dapat dilayankan di perpustakaan secara umum, yang diharapkan pula dapat menambah bacaan masyarakat, khususnya masyarakat Majalengka mengenai local content Tradisi Lisan Gaok yang berasal dari Desa Kulur Majalengka. Kegiatan penelusuran informasi ini selaras dengan tugas pusat dokumentasi lembaga perpustakaan yang dikemukakan oleh Sulistyo-Basuki (2009:89) yaitu dengan mengidentifikasi dan mengumpulkan informasi ilmiah, menganalisis dan mengolahnya ke dalam bentuk yang sesuai untuk disimpan dan ditelusuri, menyediakan tempat penyimpanan dan penyebaran, termasuk temu balik informasi bila mana diminta, sehingga dapat disimpulkan bahwa pengelolaan tradisi lisan Gaok dengan penelusuran informasi ini relevan dengan tugas pusat dokumentasi lembaga perpustakaan dalam ranah mengumpulkan informasi ilmiah yang kemudian dikelola ke dalam bentuk yang sesuai untuk disimpan, disebarluaskan, serta ditelusuri kembali.

\section{Pengolahan Artikel}

Bentuk pengelolaan selanjutnya yang telah dilakukan yaitu Pengolahan artikel-artikel penelitian yang telah ditemukan, melalui tema ini dapat diketahui proses dan tahapan-tahapan pengolahan dokumen lisan Gaok yang diantaranya terdiri dari penelusuran dan penyebaran informasi tentang Gaok. Melalui kegiatan penelusuran ternyata diketahui minimnya artikel Gaok yang tersedia secara full text. Informan menyatakan hanya menemukan tiga penelitian yang sesuai dengan kriteria yang telah ditentukan. Artikel-artikel tersebut berjudul Kajian Etnopedagogi Seni Tradisi Gaok yang ditulis oleh Nura Syifa Mutiara, Pemertahanan Tradisi Lisan Gaok di Desa Kulur Majalengka yang ditulis oleh Jafar Fakhrurozi, dan Strategi Dalang Gaok Dalam Menghadapi Modernitas Masyarakat Pendukungnya yang juga ditulis oleh Jafar Fakhrurozi. 
Kegiatan yang kemudian informan lakukan dengan tiga artikel tersebut adalah mencetak dan meletakkan di ruang referensi serta dijadikan koleksi, kegiatan ini selaras dengan tugas pusat dokumentasi lembaga perpustakaan yang dikemukakan oleh Sulistyo-Basuki (2009:89) dengan menganalisis dan mengolah ke dalam bentuk yang sesuai untuk disimpan dan ditelusuri kembali, kemudian menyediakan tempat penyimpanan dan penyebaran terkait artikel Gaok.

Koleksi yang memuat informasi yang khas dan unik tentang suatu daerah dapat dijumpai di perpustakaan, koleksi tersebut dinamakan local content, sehingga dokumen tradisi lisan Gaok dapat dikategorikan sebagai local content. Koleksi local content merupakan salah satu koleksi yang dibutuhkan masyarakat dan dapat membantu masyarakat dalam mengetahui seni, sejarah, dan budaya yang berkenaan dengan sifat lokal daerah. Kegiatan pengelolaan koleksi local content merupakan tanggung jawab lembaga perpustakaan (Rosyid, 2019). Hal ini, sesuai dengan pasal 22 ayat 2 Undang Undang Dasar No.43 Tahun 2007 tentang perpustakaan, yang menyatakan bahwa perpustakaan adalah lembaga yang memiliki fungsi mendukung pelestarian hasil budaya daerah masing-masing dan memfasiltasi terwujudnya masyarakat pembelajaran sepanjang hayat. Namun, sangat disayangkan sejauh ini perpustakaan tersebut belum mempunyai ruangan khusus yang menyimpan koleksi local content sehingga dokumen tradisi lisan Gaok hanya dapat disimpan di ruang referensi.

\section{Menulis Resensi Gaok}

Bentuk Pengelolaan lain yang dilakukan untuk melestarikan tradisi lisan Gaok adalah menulis resensi tentang Gaok. Salah satu pustakawan yang berada di perpustakaan daerah Majalengka, aktif dalam menulis seni tradisional dari berbagai daerah. Tidak hanya tradisi dari Majalengka namun juga seni tradisional dari Cirebon, contohnya seni tradisional Sintren. Tulisan tentang ragam seni tradisional tersebut ditulis dalam bentuk buku dan kemudian disimpan sebagai koleksi perpustakaan pribadi.

Berawal dari kegiatan tulis menulis dan penelusuran informasi tentang seni tradisional maka, pada tahun 2016 informan mulai menulis resensi mengenai Gaok yang berisi tentang sejarah dan asal usul Gaok, pemaknaan Gaok, dan tokoh adat yang aktif berkecimpung dalam menghidupkan Gaok. Kegiatan menulis ini sesuai dengan peran pustakawan, menurut Adelia (2016) yang menyatakan bahwa pustakawan dapat berperan dalam mengelola hasil kebudayaan melalui metode dokumentasi yang "ramah" dengan karakteristik yang ada di masyarakat. Pada kegiatan dokumentasi tersebut menghasilkan sebuah database yang mengomunikasikan dan memiliki kekuatan untuk menunjukkan kepada dunia bahwa kebudayaan "tersebut "adalah milik masyarakat "a". Penulisan resensi merupakan cara pustakawan dalam mendokumentasikan tradisi lisan Gaok dan menunjukan identitas bahwa Gaok merupakan seni tradisional yang berbentuk tradisi lisan dan milik masyarakat Desa Kulur Majalengka Jawa Barat.

Pengelolaan dokumen Gaok dengan menulis selaras dengan konteks post oleh Fitriani \& Nabila (2017) yang mana perpustakaan dapat berperan dalam mendokumentasikan dokumen lisan dengan melakukan sebuah proyek penelitian atau penulisan, sehingga dapat ditarik kesimpulan bahwa pustakawan yang ada di lembaga perpustakaan tersebut melakukan pendokumentasian terhadap tradisi lisan Gaok dengan melakukan sebuah proyek penulisan mengenai Gaok.

\section{Diseminasi Resensi Gaok}

Diseminasi (Dissemination) adalah kegiatan dalam menyebarkan suatu informasi yang bertujuan agar informasi yang disebarkan dapat dimanfaatkan. Penulisan Gaok dilanjutkan dengan mendiseminasikan karya tulis tersebut, dalam hal ini pustakawan mendokumentasikan dengan cara melakukan penyebaran sebuah karya yang sesuai dengan definisi dokumentasi oleh Reitz (2009:59) yang mana dokumentasi sendiri diartikan sebagai sebuah proses sistematis yang mengumpulkan, menyimpan, mengambil, serta menyebarluaskan sebuah dokumen. Selain sebagai 
cara mengenalkan tradisi lisan Gaok, kegiatan diseminasi ini juga sebagai cara untuk memenuhi angka kredit tugas fungsional sebagai pustakawan. Salah satu tujuan diseminasi resensi Gaok adalah ke Perpustakaan Nasional Republik Indonesia.

\section{Perencanaan dalam Pengelolaan Tradisi Lisan Gaok}

Perencanaan menjadi tema ketiga yang ditemukan dari hasil analisis data. Tema perencanaan ini muncul sebagai tindak lanjut dari kegiatan pengelolaan dengan tujuan untuk mencapai target yang lebih baik lagi dalam kegiatan pengelolaan Gaok, perpustakaan tersebut mengundang mitra luar seperti pelopor yang menerbitkan tentang Gaok, penulis yang aktif dalam meneliti mengenai Tradisi Lisan Gaok, dan tokoh-tokoh yang berkonstribusi aktif dalam menghidupkan Tradisi Lisan Gaok di daerah Majalengka untuk bekerja sama dengan pustakawan dalam kegiatan pelatihan menulis mengenai kebudayaan daerah, dalam hal ini Tradisi Lisan Gaok itu sendiri. Kegiatan tersebut mentarget siswa-siswa sekolah di sekitar Majalengka dan pelaksanaanya bertepatan dengan hari wajib kunjung siswa sekolah ke perpustakaan. Perencanaan ini sesuai dengan konteks Measures oleh Fitriani \& Nabila (2017) yang mana perpustakaan dapat mengelola dan memberdayakan masyarakat untuk terlibat langsung dalam pengelolaan dokumen lisan, karena pada dasarnya sebuah dokumen lisan tidak ada artinya tanpa sebuah praktek. Perpustakaan tersebut berencana akan melibatkan masyarakat untuk ikut melakukan pengelolaan dan pelestarian terhadap tradisi lisan Gaok di daerah Majalengka.

Perencanaan lain yang dilakukan adalah dengan mengenalkan tradisi lisan Gaok yang rencananya akan ditampilkan pada acara launching perpustakaan baru, baik itu perpustakaan sekolah, perpustakaan masyarakat, atau taman bacaan masyarakat, selain itu perencanaan lain yang akan ditempuh adalah dengan mempromosikan Gaok melalui website ataupun blog yang akan dibuat oleh pihak perpustakaan yang bersangkutan. Ditambah melalui blog pribadi milik pustakawannya, dan melalui aplikasi digital yang dimiliki dapat dimanfaatkan oleh masyarakat Majalengka secara terbuka. Perpustakaan tersebut juga menginginkan Gaok dalam kemasan yang berbeda, seperti film atau video jika ada pihak yang berkenan membuatnya.

Perencanaan dalam pengelolaan dokumen lisan diperlukan untuk mengetahui sejauh mana nantinya Gaok akan dikelola, sehingga Gaok senantiasa dapat dilestarikan dan harapan ke depannya dapat lebih dikenal oleh masyarakat secara luas, khususnya masyarakat Majalengka.

Dari penjelasan ketiga tema tersebut, dapat diketahui bahwa masing-masing tema saling memiliki keterkaitan. Dalam arti, tema yang satu mempengaruhi munculnya tema yang lain. Sebagai contoh, tema yang pertama yaitu "Motivasi" mempengaruhi munculnya kegiatan "Pengelolaan dan Perencanaan" secara garis besar, "Motivasi" menjadi sebab utama dari terlaksananya suatu kegiatan, termasuk dalam kegiatan pengelolaan Gaok yang dilakukan oleh pustakawan. Tema kedua, yaitu pengelolaan, tema ini juga mempengaruhi adanya tema perencanaan. Secara umum, sebuah program ataupun kegiatan harus memiliki perencanaan ke depan untuk mencapai target yang lebih baik lagi, maka dengan ini pengelolaan terhadap Gaok harus lebih baik lagi ke depannya.

\section{Kesimpulan}

Dengan wujud untuk melestarikan kebudayaan Indonesia berupa tradisi lisan Gaok serta sebagai langka untuk menghindarinya dari kepunahan, maka perpustakaan melakukan kegiatan pengelolaan dengan cara penelusuran informasi tentang tradisi lisan Gaok. Kegiatan ini kemudian dilanjutkan dengan mengolah artikel yang telah diperoleh. Pengolahan ini meliputi pencetakan artikel, penyimpanan, dan melayankan artikel. Tahap selanjutnya, pustakawan menulis resensi mengenai Gaok dan dikirimkan ke Perpustakaan Nasional Republik Indonesia, dengan harapan banyak orang mengetahui tentang tradisi lisan Gaok tersebut. Secara keseluruhan kegiatan pengelolaan tersebut sangat relevan dengan tugas dari pusat dokumentasi, yaitu dengan mengidentifikasikan dan mengumpulkan informasi ilmiah mengenai Gaok, mengolahnya ke 
dalam bentuk yang sesuai untuk disimpan dan ditelusuri kembali, serta dengan menyebarluaskannya. Berdasarkan keseluruhan kegiatan pengelolaan tradisi lisan Gaok ini pula dapat dilihat bahwa seorang pustakawan dan lembaga perpustakaan memiliki tugas untuk mengelola hasil dari kebudayaan dan bentuk lain dari sebuah dokumen.

\section{Ucapan Terima Kasih}

Terima kasih atas bantuan Kepala Bidang Perpustakaan dan pustakawan Dinas Kearsipan dan Perpustakaan Kabupaten Majalengka yang telah memberikan data dan informasi yang dibutuhkan penulis selama proses penelitian.

\section{Referensi}

Adelia, N. (2016). Pustakawan dan Pengetahuan Tradisional: Studi tentang Urgensi dan Peran Pustakawan dalam Pengetahuan Tradisional. Record and Library Journal, 2 (1): 56. doi:10.20473/rlj.V2-I1.2016.51-57

Braun, V., \& Clarke, V. (2006). Using thematic analysis in psychology. Qualitative Research in Psychology, 3(2), p.77-101. Retrieved from http://eprints.uwe.ac.uk/11735/2/thematic_analysis_revised_-_final.pdf

Duija, I. N. (2005). Tradisi Lisan, Naskah dan Sejarah: Sebuah Catatan Politik Kebudayaan. Wacana: Jurnal Ilmu Pengetahuan Budaya, 2(7), retrieved from http://wacana.ui.ac.id/index.php/wjhi/article/view/296/279

Fitriani, Dian Novita \& Nabila, Niswa Sba (2017). The Role of Library in Managing Oral Document (Theoritical Studies on Indigenous Knowledge for Disaster Management in Simeuleu Island). Conference: $5^{\text {th }}$ International Conference as Asian Special Libraries (ICoASL 2017). Yogyakarta-Indonesia: Sunan Kalijaga State Islamic University. Retrieved from

https://www.researchgate.net/publication/316914808_The_Role_of_Library_in_Managin g_Oral_Document_Theoretical_Studies_on_Indigenous_Knowledge_for_Disaster_Mana gement in Simeuleu_Island

Heriyanto (2018). Thematic Analysis sebagai metode menganalisis data untuk penelitian kualitatif.

Anuva: Jurnal Kajian Budaya, Perpustakaan, dan Informasi, 2(3); 317-324, doi: 10.14710/anuva.2.3.317-324

Kementerian Pendayagunaan Aparatur Negara dan Reformasi Birokrasi RI .Keputusan Menteri Pendayagunaan Aparatur Negara RI. No.9 Tahun 2014.Tentang Jabatan Fungsional Pustakawan dan Angka Kreditnya.

Lasa, HS. (2009). Peran Perpustakaan dalam Melestarikan Budaya dan Membangun Peradaban. Retrieved from http://repository.umy.ac.id/bitstream/handle/123456789/6373/Peran\%20Perpustakaan\%2 0dalam\%20Melestarikan\%20Budaya\%20dan\%20Membangun\%20\%0c\%20Peradaban.pd f?sequence $=1 \&$ isAllowed $=y$

Nashiuddin, W. \& Aulianto, D. R. (2015). Strategi Peningkatan Kompetensi dan Profesionalisme Pustakawan di Perpustakaan Khusus. Jurnal Perpustakaan Pertanian, 2(24), doi: http://dx.doi.org/10.21082/jpp.v24n2.2015.p51-58Reitz, Joan M. (2009). Dictonary for Library and Information Science. London: Libraries unlimited: a member of the Greenwood Publishing Group

Reitz, J. M. (2009). Dictonary for Library and Information Science. London: Libraries unlimited: a member oft he Greenwood Publishing Group

Rosyid, S. F. Pengelolaan Koleksi Local Content (Muatan Lokal) Banten Corner di Dinas Perpustakaan Dan Kearsipan Provinsi Banten. Retrieved from file:///C:/Users/TOSHIBA/Downloads/22815-46253-1-PB.pdf

Setiawan, I. (2018). Gaok, Tradisi Lisan Majalengka yang Hampir Punah. Retrieved April 72019

To cite this document:

Septa \& Haeriyanto. (2020). Gaok's Oral Tradition Document Management as a Manifestation Of Cultural Preservation in The Library.

Record and Library Journal, 6(1), 89-98.

Open access under Creative Commons Attribution-Share A like 4.0 International Licence 
from https://kebudayaan.kemdikbud.go.id/bpnbjabar/2018/01/15/gaok-tradisi-lisanmajalengka-yang-hampir-punah/

Sulistyo-Basuki. (2009). Pengantar Ilmu Perpustakaan. Jakarta: Gramedia Pustaka Utama

Sumitri, N. W., and I Wayan.(2016). Bahasa Ritual dan Kekusaan Tradisional Etnik Rongga (Ritual Languange and Traditonal Power in Rongga). Paper presented at the KIMLI 2016 (the International Conference of the Indonesian Linguistic Society). Bali 24-27 Agustus 2016

Turner, Deborah. A. (2009). Conceptualizing Oral Document. Information Research, 12 (4). Retrieved from http://informationr.net/ir/12-4/colis/colis32.html

, Deborah. A. (2015). Reconsidering Library Collections: Comunnity Services as Documents. Proceedings from the $12^{\text {th }}$ the Annual Meeting of the Document Academy. Retrieved from http://ideaechange.uakron.edu/docam/vol2/issI/17

Undang-Undang Republik Indonesia Nomor 43 Tahun 2007 Tentang Perpustakaan 